\title{
Modelling the mode choice behaviour of visitors to \\ Expo 2010
}

1 Yuchuan Du MPhil, PhD

Professor, Key Laboratory of Road and Traffic Engineering of the Ministry of Education, Tongji University, Shanghai, China

2 Shengchuan Jiang $B S C(E n g)$

Research Assistant, Key Laboratory of Road and Traffic Engineering of the Ministry of Education, Tongji University, Shanghai, China
3 Lijun Sun MPhil, PhD

Professor, Dean, Key Laboratory of Road and Traffic Engineering of the Ministry of Education, Tongji University, Shanghai, China

4 Sze-Chun Wong MPhil, PhD, FCILT, FHKIE, FHKSTS, MASCE, MITE, MIHT

Professor, Director, Institute of Transport Studies, Department of Civil Engineering, University of Hong Kong, Hong Kong, China
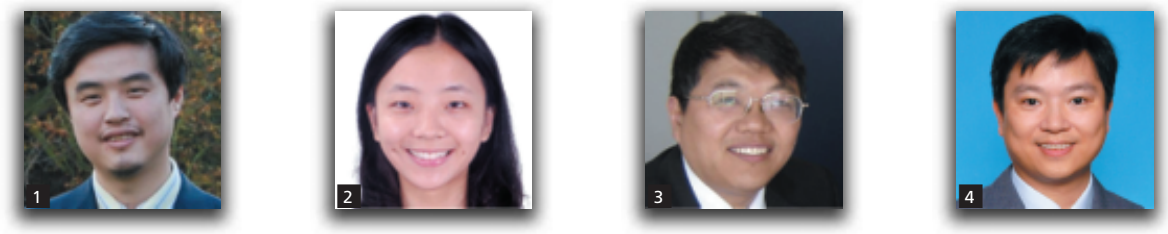

The purpose of the present study was to obtain a better understanding of the mode choice behaviour of visitors to Expo 2010 Shanghai and the effectiveness of various traffic management policies to reduce private transport use. Due to the possible range of survey respondents, a two-stage gradual stated preference survey method was used. Based on a large-scale stated preference survey conducted among tourists in an airport, a train station and highway service stations in Shanghai, three versions of a mixed logit model for local and out-of-town visitors were developed. The results suggest that local visitors were more sensitive to travel cost than total travel time, whereas out-of-town visitors were particularly concerned about total travel time. A scenario analysis reveals that establishing a restricted traffic zone, adjusting parking rates and providing priority lanes for Expo buses had different effects on trip mode choice. These policies should thus be implemented in combination to achieve the aim of reducing private transport use to less than $10 \%$. An additional finding is that the Expo shuttle bus is a more attractive public transport mode than the subway among Expo visitors.

\section{Introduction}

It is expected that Expo 2010 Shanghai will attract approximately 70 million visitors over the 184 days of the event, with an average of 400000 visitors daily and 800000 visitors on peak days (Organization Committee of Expo 2010 Shanghai, 2005; Yin et al., 2007). As Expo Park is located in the centre of Shanghai, this mega-event is regarded by many experts to be one of the greatest transport and logistics challenges in the world (Yin et al., 2007). The enormous number of visitors requiring transport, combined with the congested urban road network and limited parking provision, will make private transport use problematic during Expo. Hence, greater utilisation of public transport will be necessary to reduce the reliance on private car use (Winebrake et al., 2008). Exploring the mode choice behaviour of Expo visitors is the keystone of traffic planning for Expo 2010 Shanghai, and especially the efficiency assessment of different traffic policies.

Over the past few decades, research interest in the link between travel choice behaviour and the contribution of various independent variables has blossomed. Stated preference techniques, which have a strong theoretical basis, are widely used in research in this field to predict the probability of individual choice behaviour (Handy, 1996). The first stated preference model was developed in the 1970s as a marketing research approach to obtain a better understanding of travel behaviour (Adler and BenAkiva, 1976; Davidson, 1973). More recently, discrete choice models based on stated preference methods have become a popular option among academics, governments and consulting companies to explore many aspects of transportation, including mode choice behaviour under different traffic management policies, devices and urban forms, and the relationship between business air travel and videoconferencing (Bhat, 1997; Fowkes and Preston, 1991; Hensher and Battellino, 1997; Lu and Peeta, 2009; McMillan, 2007; Sakano and Benjamin, 2008).

Goodwin (1995) argued that the consideration of the differences among people is crucial to travel behaviour analysis. Many studies focus on distinguishing the differences of survey target groups to improve the reliability of analysis models. Hensher (1994) pointed out that it is difficult for respondents to distinguish 
between and rank more than five items at a time. Wang et al. (2000) argued that if hypothetical situations are far removed from the daily experience of respondents, then a stated preference study will generate poor models and inaccurate results. Raney et al. (2000) stated that people have a choice set of travel alternatives that differs from the total set of available alternatives. Punj and Brookes (2001) asserted that a person's subjective choice, or consideration, set comprises the choice alternatives of which the person is aware and which he or she considers feasible and acceptable. Molin and Timmermans (2009) reported that including too many attributes in survey questions causes information overload and increases the burden on respondents.

Many strategies have been proposed for distinguishing among groups of travellers, including those based on attribute cut-offs, clusters of travel attitudes, motivations or preferences, behavioural repertoires for different activities and hierarchical information integration (Anable, 2005; Bamberg and Schmidt, 2001; Cervero et al., 2009; Habib and Miller, 2009; Johansson et al., 2006; Molin and Timmermans, 2009; Steg, 2005; Swait, 2001; Tam et al., 2008; Van Exel et al., 2005).

The objective of the present study is to investigate the differences in trip mode choice behaviour among potential Expo visitor groups to support the scenario analysis of traffic management policies for Expo 2010 Shanghai. Due to differences in Expo visitor departure areas and their influence on trip mode behaviour, a two-stage gradual stated preference survey method was used to distinguish the various types of Expo visitors and to develop variable multinomial logit models for local and out-of-town Expo visitors.

The remainder of this paper is organised as follows. The next section describes the survey mechanism, design and implementation among potential visitors to Expo 2010 Shanghai, and illustrates the statistical attributes of the first-stage survey data to support the categorisation of Expo visitor groups. This is followed by a consideration of the variables; the selection of model structures from among the multinomial logit (MNL) model, the nested logit (NL) model and the mixed logit (ML) model; and the estimation of discrete choice models to analyse the different Expo visitor groups departing from different places and in different trip chains. The chosen mixed logit models are then used to estimate the trip mode share for the different visitor groups under various policies for Expo traffic management, and the effects of switching from private to public transport are discussed. The final section includes some concluding comments and suggestions for traffic planning for Expo 2010 Shanghai.

\section{Design of a two-stage stated preference survey}

The level of transport demand in Shanghai during Expo 2010 will be very high because of the great numbers of local and out-oftown visitors, including those from the Yangtze Delta, other regions of China such as Hong Kong, Macau and Taiwan, and foreign countries. The registration report of the Expo 2010 Shanghai Committee indicates that Shanghai visitors will account for $25 \%$ of total visitors, visitors from the Yangtze Delta $40 \%$, visitors from other regions of China $30 \%$ and visitors from overseas 5\%, as shown in Figure 1.

Due to the range of visitors to Expo 2010 Shanghai and their differing attributes, it will obviously be difficult to obtain satisfactory results by placing all Expo visitors in a single group for analysis and modelling. In addition, as the World Expo has not previously been held in China, there is no reference to help understand or predict visitor trip mode choice behaviour over the duration of this mega-event. Against this backdrop, this study develops a two-stage gradual stated preference survey method for the in-depth study of Expo visitor trip mode choice behaviour. The survey procedure is presented in Figure 2.

The stage 1 survey, which addressed mode choice behaviour, had two purposes: to determine the potential trip mode choices of visitors from different departure areas and the differences in travel behaviour among visitor groups, and to determine the threshold value of the influencing variables, including travel cost, walking time, departure interval and so forth. The survey findings served as the basis for specifying the variable values in the stage 2 survey. To obtain information about the behaviour and travel characteristics of potential visitors from the urban areas of Shanghai and other cities of China, and especially those in the Yangtze Delta, the stage 1 survey was conducted at Hongqiao Airport and South Railway Station in Shanghai and at service areas on the Shanghai-Nanjing and Shanghai-Hangzhou expressways in December 2008. In total, 1268 useable questionnaires were collected, which is a sufficient sample size because no more than 10 market segments were considered and 75-100 interviews were required for each segment (see Chapter 3 of Ortuzar and Willumsen (2001)).

The purpose of the stage 2 survey, which addressed multiscenario-comparison choice behaviour, was to obtain data for the development of a trip choice model of Expo visitors. This survey explored the influence of parking rates, walking time and travel time on trip mode choice to support travel demand forecasting for each means of transport to Expo, and analysed various traffic management policies for Expo so as to develop strategies to effect a switch from private to public transport use. The stage 2 survey was designed on the basis of the findings of the stage 1 survey. It included fewer variables and fewer variable levels based on the characteristics of visitors from different departure areas to improve the modelling choice behaviour. The shares of various transport modes were studied to determine the influence of traffic management policies. To guarantee consistency, the stage 2 survey was conducted in July 2009 in the same places as the stage 1 survey, and 743 effective questionnaires were recovered, in which 389 questionnaires were Shanghai local visitors, 77 were out-of-town one-day-trip visitors and 277 were out-of-town lodging visitors. 


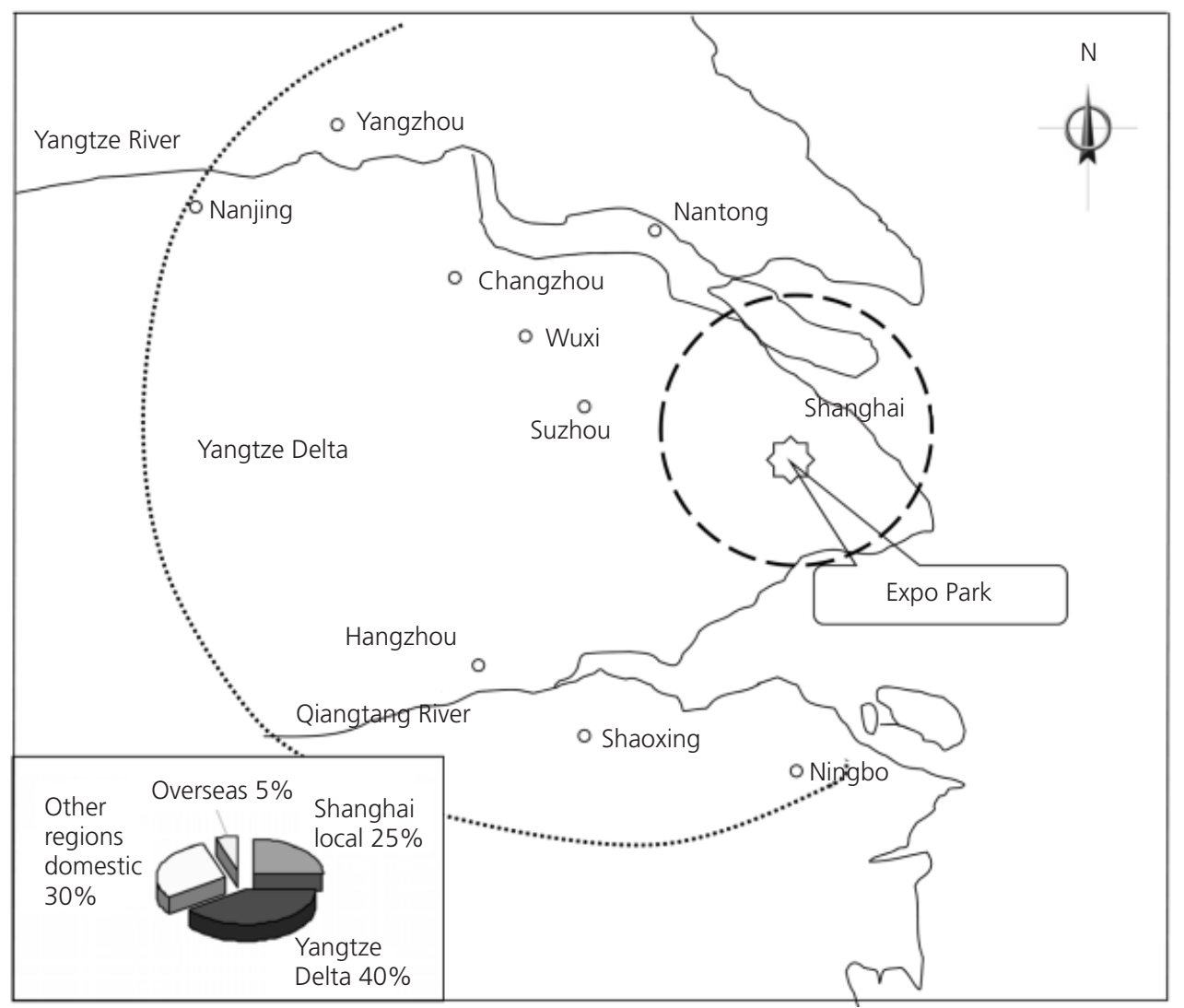

Figure 1. Distribution of Expo visitors

The characteristics of the assorted visitor groups, which are coming from different departure areas, were analysed to gain a better understanding of the differences in travel behaviour among these groups. The distribution of travel times acceptable to the survey respondents is shown in Figure 3. Among the day-trip visitors, the acceptable travel time is generally over $90 \mathrm{~min}$ because of the long distances involved. Their first choice is thus to shorten their travel time and take direct private transport, which is quite different from the choice of local and out-of-town lodging visitors.

Figure 4 shows an obvious difference between Shanghai and outof-town lodging visitors in choice of trip mode without constraints, although the two types of visitors prefer the same trip mode alternative and have similar acceptable travel times. Most local visitors prefer private transport by car, whereas most out-oftown lodging visitors prefer to use a taxi. The data show the different travel attributes favoured by the out-of-town day-trip, Shanghai and out-of-town lodging visitors. Clearly, there are great differences in their trip mode choice behaviour. In the stage 2 survey, group classification was carried out based on the attributes favoured by these three types of visitors.

Many factors influence trip mode choice, including travel time, travel cost, comfort and safety and the personal attributes of the survey respondents, such as income and age. Among these factors, comfort and safety are hardest to quantify. This study thus explored the influence of travel time and cost on travel choice behaviour among potential Expo visitors. In the stage 1 survey, the choice distribution analysis focused on determining the travel cost, walking time and departure interval acceptable to visitors to narrow the range of choices for the stage 2 survey. The distributions of the travel cost, Expo shuttle bus departure intervals and walking times acceptable to the survey respondents are shown in Figure 5. Taking acceptable travel cost as an example, the figure shows that $75 \%$ of potential visitors believe an acceptable one-way travel cost to be around 50 Yuan per person. In the design of the stage 2 questionnaire, the highest travel cost was thus set at around 50 Yuan per person, so that realistic choices could be presented to the survey respondents.

\section{Development of a discrete selection model}

This section describes the process of model development utilising the aforementioned survey data. Preliminary analysis was performed to determine the most suitable model of trip choice behaviour and valid coefficients for the survey data. The coefficients of multinomial logit models for different visitor groups were then deduced using the survey data. The significance of the model coefficients is briefly described. 


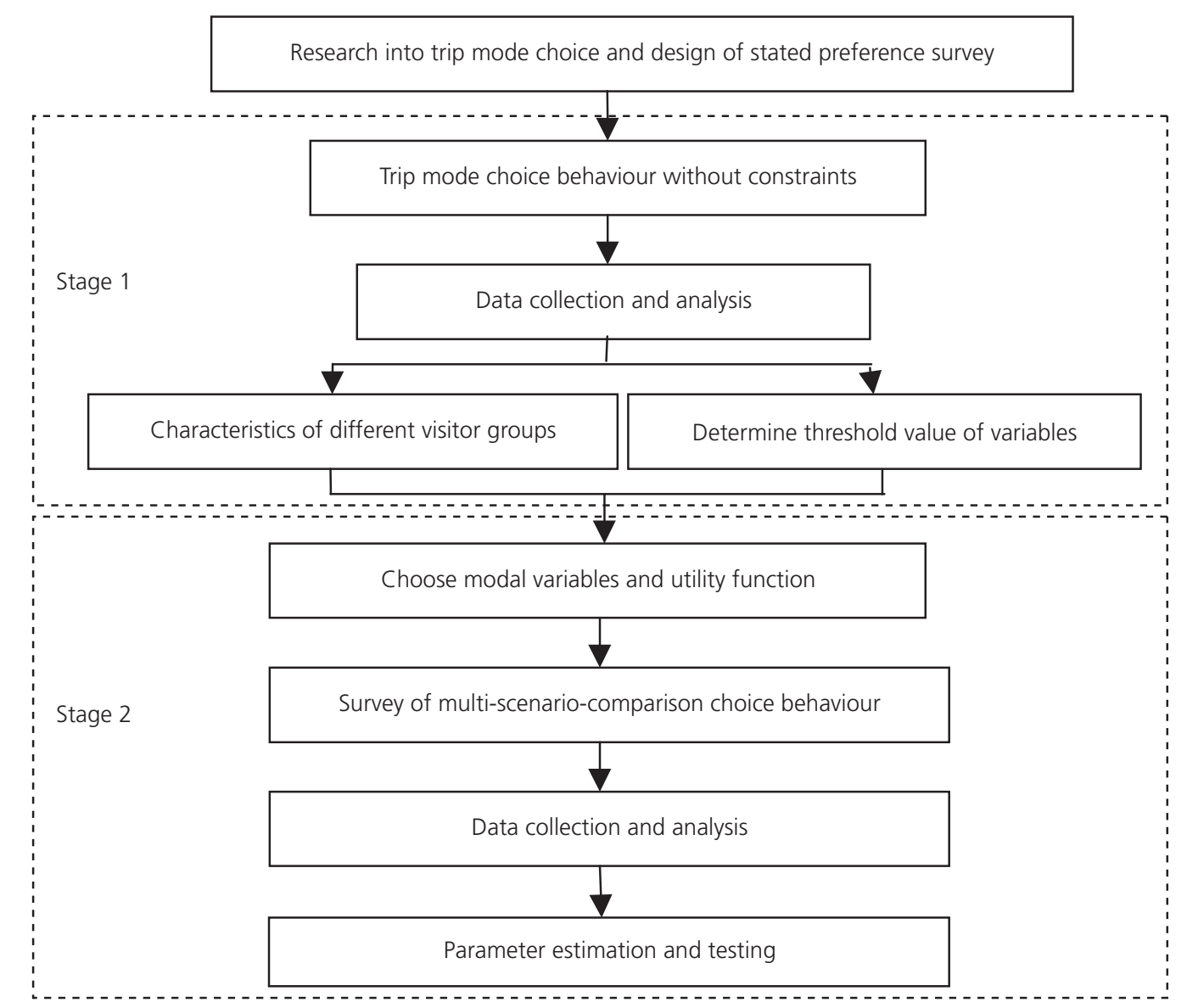

Figure 2. Procedure of the two-stage gradual stated preference survey

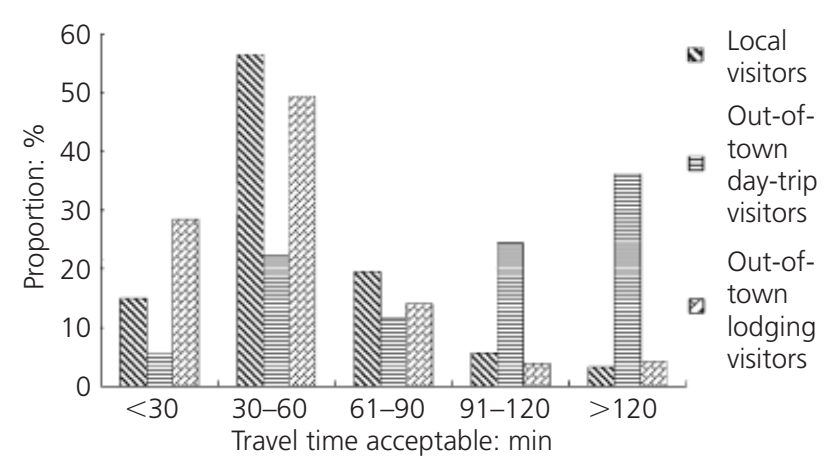

Figure 3. Distribution of acceptable travel times

\subsection{Choice of model variables}

Based on the results of the stage 1 survey, the variables that significantly influence trip mode choice, including time, cost and departure area, were considered. The survey data reveal that visitor departure area greatly influenced trip mode choice, yet it is difficult to model this influence as a quantifiable factor. Influence is taken as the basis for model classification and is standardised in accordance with the respective source areas,

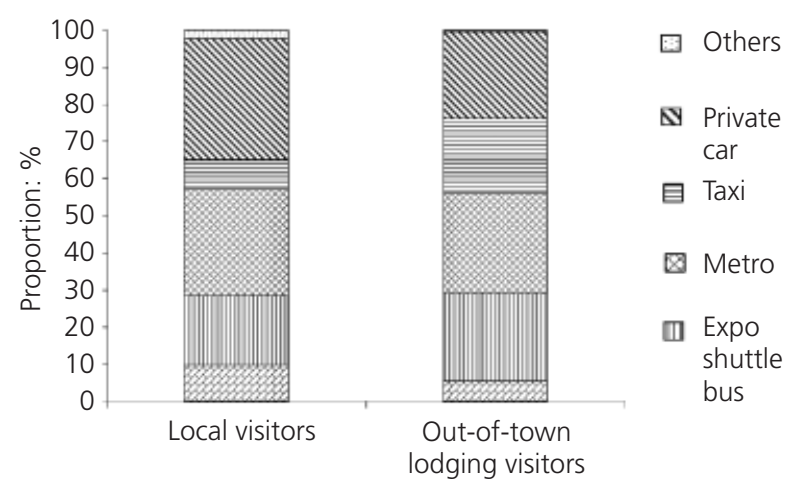

Figure 4. Comparison of trip mode preferences of local and out-of-town lodging visitors

which are represented by fixed-effect dummy variables in the model. The two external factors with the greatest influence over trip mode choice behaviour are time and travel cost. Time is classified into the categories of walking, waiting and riding time, and travel cost includes the ticket cost, parking rates at transfer points outside the urban area of Shanghai or around Expo Park 
Modelling the mode choice behaviour of

visitors to Expo 2010

Du, Jiang, Sun and Wong
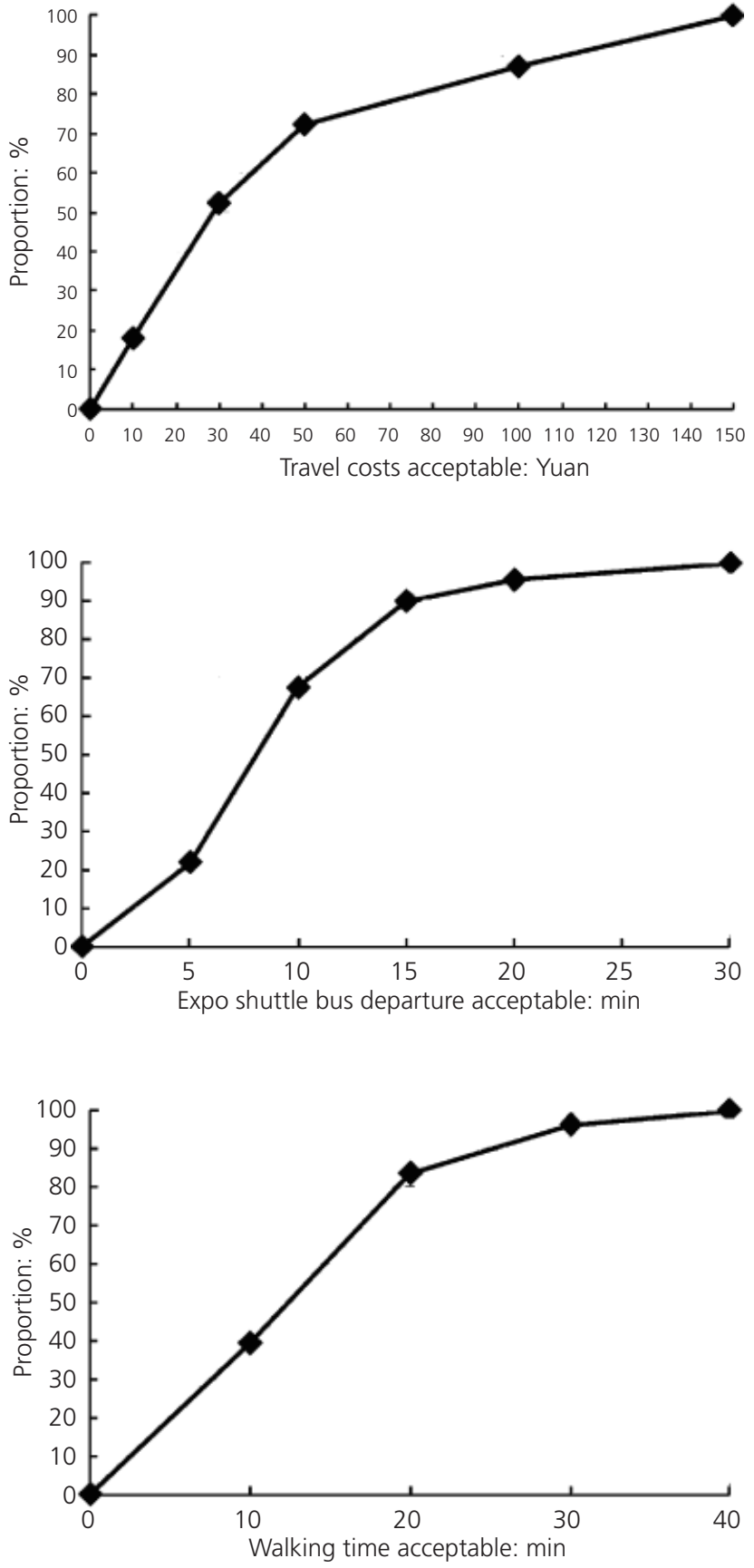

Figure 5. Distribution of choice results for the variables in the stage 1 survey

and fuel costs, among others. The variables and their associated parameters used in the development of the model specification are shown in Table 1.

Four MNL models were tested to determine the best model specification. The results of the pre-estimation of the parameters for the four models are shown in Table 2. A probability level of $<0.05$ was used as the threshold for statistical significance.
The table shows that the number of divisions of time and travel cost give poor results, perhaps because the survey respondents could not clearly distinguish between the rates of time and travel cost items. Thus, based on the results of the stage 1 survey, walking time, travel time (waiting time + riding time) and travel cost were chosen as the variables for analysis. In surveys conducted in China, true personal income and private car ownership data are usually hard to obtain because this is considered private information. Hence, personal income was not used as a model variable in the analysis.

\subsection{Comparison of discrete choice models}

The development of stated preference survey techniques has made several new and powerful random utility choice modelling tools available. In this study, the best-fitting model form was derived by comparing the MNL model, the NL model and the ML model.

The multinomial logit model is the simplest and most popular discrete choice model. It is characterised by a terse mathematical form and an easily understood and tangible meaning. The probability of selection ranges between zero and one, the sum of one determining choice branch selection probability, and so forth. Based on the choice of the aforementioned variables, the MNL utility function for the Expo trip mode choice analysis can be defined as

1. $U_{\text {in }}=V_{\text {in }}+\varepsilon_{\text {in }}$

where $U_{i n}$ is a net utility of trip mode choice $i$ for individual $n$, $V_{i n}$ is a function of the measured attributes of trip mode choice $i$ for individual $n$ and $\varepsilon$ is a random part which reflects particular tastes of each individual. The first part of the sum can be expressed as

\section{2. $V_{\text {in }}=A_{i}+P W \times W K+P I \times W T+P C \times T C$}

where the parameters $A_{i}$ are constants for the trip modes. The trip mode choice set is $C=\{i=1$ (taxi); 2 (subway); 3 (Expo shuttle bus); 4 (private car) $\}$, and $\mathrm{A} 1=0$.

The nested logit model was specially designed to account for the problem that alternatives are not independent of each other. Dependencies between trip mode alternatives can be represented by the scale of differences in the error components of the various facets. The nested structure for an Expo trip is depicted in Figure 6.

Within this nested structure, the utility function is as follows

3. $U(d, i)=V_{d}+V_{d i}+\varepsilon_{d}+\varepsilon_{d i}$ 


\begin{tabular}{lccc}
\hline Explanation & $\begin{array}{c}\text { Measurement } \\
\text { unit }\end{array}$ & $\begin{array}{c}\text { Abbreviation/ } \\
\text { variable }\end{array}$ & $\begin{array}{c}\text { Associated } \\
\text { parameters }\end{array}$ \\
\hline Constant taxi & - & - & $A_{1}$ \\
Constant subway & - & - & $A_{2}$ \\
Constant Expo shuttle bus & - & - & $A_{3}$ \\
Constant private car & - & - & $A_{4}$ \\
Walking time & min & $W K$ & $P W$ \\
Waiting time & min & $W T$ & $P I$ \\
Riding time & min & $R T$ & $P R$ \\
Total travel time & min & $T$ & $P T$ \\
Total travel cost & Yuan & $T C$ & $P C$ \\
Income & Yuan & $I C$ & $P S$ \\
Car ownership & - & $C O$ & $P O$ \\
Table 1. Variables and parameters used & & \\
\hline
\end{tabular}

\begin{tabular}{|c|c|c|c|c|c|c|c|c|}
\hline \multirow[t]{2}{*}{ Variables } & \multicolumn{2}{|c|}{ Model 1} & \multicolumn{2}{|c|}{ Model 2} & \multicolumn{2}{|c|}{ Model 3} & \multicolumn{2}{|c|}{ Model 4} \\
\hline & Coefficient & $t$-statistic & Coefficient & t-statistic & Coefficient & t-statistic & Coefficient & t-statistic \\
\hline$A_{1}$ & 0 & - & 0 & - & 0 & - & 0 & - \\
\hline$A_{2}$ & $1 \cdot 56$ & $6 \cdot 9 * *$ & $1 \cdot 61$ & $7 \cdot 6^{* *}$ & $1 \cdot 56$ & $6 \cdot 9 * *$ & 0.22 & 0.66 \\
\hline$A_{3}$ & 1.87 & $10 \cdot 7 * *$ & 1.92 & $15 \cdot 7 * *$ & 1.87 & $10 \cdot 7 * *$ & $2 \cdot 7$ & $7 \cdot 56^{* *}$ \\
\hline $\mathrm{A}_{4}$ & $1 \cdot 51$ & $2 \cdot 89 * *$ & +1.56 & $3 \cdot 37 * *$ & $\quad 1.51$ & $2 \cdot 89 * *$ & $13 \cdot 02$ & $5 \cdot 8 * *$ \\
\hline PW & & & & & & & -0.426 & $-5 \cdot 3 * *$ \\
\hline $\mathrm{Pl}$ & & & & & & & -0.452 & $-2 \cdot 7 * *$ \\
\hline$P R$ & & & & & & & -0.049 & $-5 \cdot 18 * *$ \\
\hline PT & -0.009 & $-5 \cdot 2 * *$ & -0.008 & $-5 * *$ & -0.009 & $-5 \cdot 2 * *$ & & \\
\hline PC & -0.021 & $-3 * *$ & -0.022 & $-3 * *$ & -0.021 & $-3 * \star$ & $-0 \cdot 105$ & $-6 \cdot 1 * *$ \\
\hline PS & & & $1.22 \times 10^{-3}$ & 0.6 & & & & \\
\hline $\mathrm{PO}$ & & & & & $1.49 \times 10^{-8}$ & $1.51 \times 10^{-14}$ & & \\
\hline Adjusted $\rho^{2}$ & \multicolumn{2}{|c|}{0.2307} & \multicolumn{2}{|c|}{0.2236} & 0.22 & 236 & \multicolumn{2}{|c|}{0.2239} \\
\hline
\end{tabular}

Table 2. Model parameter pre-estimation results

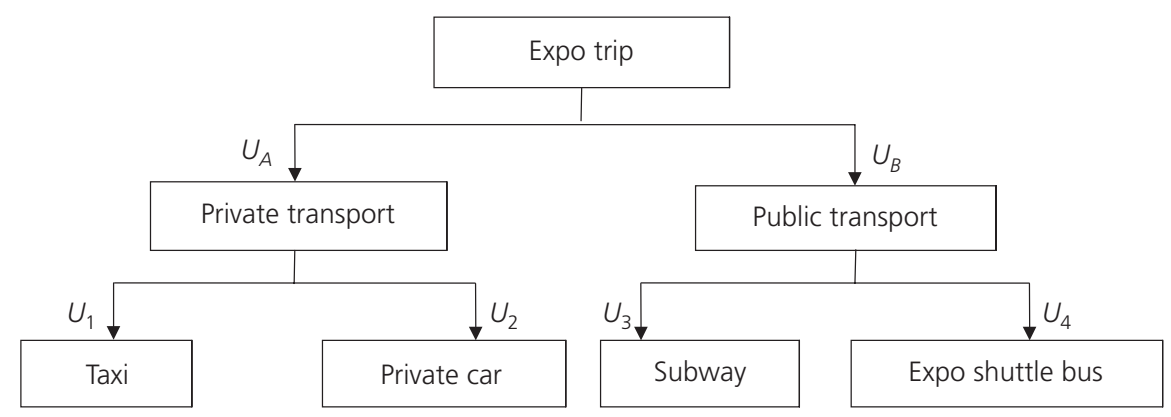

Figure 6. Choice of trip mode nested by transport type 
Transport

Volume 165 Issue TR1
Modelling the mode choice behaviour of

visitors to Expo 2010

Du, Jiang, Sun and Wong where $d$ is the nest code in the upper level and $i$ represents an alternative in the Expo trip mode choice set $\mathrm{C}$.

The mixed logit is a fully general statistical model that is used to examine discrete choices. The mixed logit model is often used to overcome the limitations of the standard logit model, which include random taste variation, unrestricted substitution patterns, and correlation among unobserved factors over time (McFadden and Train, 2000). The mixed logit model has been in use for many years but has only become fully applicable since the advent of simulation in recent years. In the mixed logit model used in this study, the utility function of person $n$ from Expo trip mode alternative $i$ is specified as

4. $U_{n i}=\theta_{n} X_{n i}+\varepsilon_{n i}$

where $X_{n i}$ represents observed variables that relate to the alternatives and the decision maker; $\theta_{n}$ is a vector of the coefficients of these variables for person $n$ and thus represents that person's preferences, and $\varepsilon_{n i}$ is a random term that is an independent and identically distributed (IID) extreme value. Two kinds of ML models with different assumed coefficient distribution are examined. In model ML1, the coefficients of walking time, total travel time and total travel costs are given independent normal distributions. In model ML2, the coefficients of walking time and total travel time are given independent normal distributions.

The results of the pre-estimation of the parameters for the MNL model, NL model and the two kinds of ML models are listed in Table 3. The goodness of fit of the logit models is assessed by using the adjusted $\rho^{2}$ statistic. An adjusted $\rho^{2}$ value between $0 \cdot 20$ and $0 \cdot 40$ suggests a very good model fit.

The adjusted $\rho^{2}$ statistic values for the models fluctuate between $0 \cdot 22$ and $0 \cdot 23$, which is a small interval within the 'good fit' range. This implies that all of the logit models have a statistically similar goodness of fit. Given the rationality of the theoretical foundation of the mixed logit model, the best fitting mixed logit model ML2 is chosen for the scenario analysis of Expo traffic management, rather than ML1, which assumes all of the coefficients to have a normal distribution.

\subsection{Parameter estimation for the three visitor groups}

Parameter estimation was carried out on the basis of the 743 questionnaires obtained in the stage 2 survey. Of these, 389 represent a departure area in Shanghai; 77 a departure area outside Shanghai no more than a day's trip away; and 277 a departure area outside Shanghai and thus requiring lodging. This gives a total of $2583[(389 \times 3)+(77 \times 4)+(277 \times 4)]$ mode choice observations. The results of the estimation of the trip choice model parameters for the local, out-of-town day-trip and

\begin{tabular}{|c|c|c|c|c|c|c|c|c|}
\hline \multirow{2}{*}{$\begin{array}{l}\text { Model } \\
\text { Variables }\end{array}$} & \multicolumn{2}{|c|}{ MNL } & \multicolumn{2}{|c|}{$\mathrm{NL}$} & \multicolumn{2}{|c|}{ ML1 } & \multicolumn{2}{|c|}{ ML2 } \\
\hline & Coefficient & t-statistic & Coefficient & t-statistic & Coefficient & t-statistic & Coefficient & t-statistic \\
\hline \multicolumn{9}{|c|}{ Constant coefficient } \\
\hline Taxi & 0 & - & 0 & - & 0 & - & 0 & - \\
\hline Tube & 1.67 & $9 \cdot 29$ & $2 \cdot 31$ & $3 \cdot 8$ & 1.67 & $-3 \cdot 6$ & 1.68 & $-3 \cdot 5$ \\
\hline Expo shuttle bus & $1 \cdot 55$ & $5 \cdot 1$ & $2 \cdot 26$ & $4 \cdot 7$ & $1 \cdot 56$ & $-4 \cdot 7$ & $1 \cdot 55$ & -4.9 \\
\hline Private car & 1.9 & $3 \cdot 14$ & $1 \cdot 13$ & $12 \cdot 6$ & $1 \cdot 91$ & $-3 \cdot 1$ & 1.91 & $-3 \cdot 1$ \\
\hline \multicolumn{9}{|c|}{ Characteristic variable coefficient } \\
\hline Walking time & -0.033 & $-11 \cdot 4$ & -0.009 & -4 & $\begin{array}{c}-0.034 \\
(0.01)\end{array}$ & $\begin{array}{l}-2 \cdot 7 \\
(2 \cdot 7)\end{array}$ & $\begin{array}{c}-0.034 \\
(0.011)\end{array}$ & $\begin{array}{l}-2 \cdot 7 \\
(2 \cdot 6)\end{array}$ \\
\hline Travel time & -0.009 & $-5 \cdot 3$ & -0.006 & $-3 \cdot 3$ & $\begin{array}{c}-0.0096 \\
\left(6.6 \times 10^{-4}\right)\end{array}$ & $\begin{array}{l}-5 \cdot 8 \\
(2 \cdot 6)\end{array}$ & $\begin{array}{r}-0.0092 \\
(0.0041)\end{array}$ & $\begin{array}{l}-5 \cdot 5 \\
(2 \cdot 1)\end{array}$ \\
\hline Travel cost & -0.025 & $-3 \cdot 24$ & -0.014 & $-2 \cdot 4$ & $\begin{array}{c}-0.025 \\
(-0.0031)\end{array}$ & $\begin{array}{l}-3 \cdot 2 \\
(-8 \cdot 7)\end{array}$ & -0.0246 & $-3 \cdot 2$ \\
\hline \multicolumn{9}{|c|}{ Other variable coefficient } \\
\hline NESTA & - & - & $1 \cdot 22$ & $11 \cdot 5$ & - & - & - & - \\
\hline NESTB & - & - & $7 \cdot 49$ & $3 \cdot 1$ & - & - & - & - \\
\hline Adjusted $\rho^{2}$ & 0.2227 & & 0.2293 & & 0.2216 & & 0.2222 & \\
\hline
\end{tabular}

For the ML models, the results in brackets are the standard deviations or corresponding t-statistic.

Table 3. Model parameter pre-estimation results 


\begin{tabular}{|c|c|c|c|c|c|c|c|c|}
\hline & \multicolumn{4}{|c|}{ Constant coefficient } & \multicolumn{3}{|c|}{ Characteristic variable coefficient } & \multirow{2}{*}{$\begin{array}{c}\text { Adjusted } \\
\rho^{2}\end{array}$} \\
\hline & Taxi & Subway & $\begin{array}{c}\text { Expo shuttle } \\
\text { bus }\end{array}$ & Private car & Walking time & Travel time & Travel cost & \\
\hline Coefficient & 0 & 1.68 & $1 \cdot 55$ & $1 \cdot 91$ & $-0.034(0.011)$ & $-0.009(0.004)$ & -0.025 & 0.2222 \\
\hline t-statistic & - & $-3 \cdot 5^{\star \star}$ & $-4 \cdot 9 * \star$ & $-3 \cdot 1 * \star$ & $-2 \cdot 7 * \star\left(2 \cdot 6^{\star \star}\right)$ & $-5 \cdot 5 * *(2 \cdot 1 *)$ & $-3 \cdot 2 * \star$ & \\
\hline
\end{tabular}

* Significant at the $5 \%$ level.

** Significant at the $1 \%$ level.

Table 4. Model parameters for the local visitor group

\begin{tabular}{|c|c|c|c|c|c|c|c|c|}
\hline & \multicolumn{4}{|c|}{ Constant coefficient } & \multicolumn{3}{|c|}{ Characteristic variable coefficient } & \multirow{2}{*}{$\begin{array}{c}\text { Adjusted } \\
\rho^{2}\end{array}$} \\
\hline & Taxi & Subway & $\begin{array}{l}\text { Expo shuttle } \\
\text { bus }\end{array}$ & Private car & Walking time & Travel time & Travel cost & \\
\hline $\begin{array}{l}\text { Coefficient } \\
t \text {-statistic }\end{array}$ & $\begin{array}{l}0 \\
-\end{array}$ & $\begin{array}{l}-0 \cdot 423 \\
-3 \cdot 2 * *\end{array}$ & $\begin{array}{l}0.421 \\
6 \cdot 6^{*}\end{array}$ & $\begin{array}{r}0 \cdot 107 \\
-4 \cdot 7 * *\end{array}$ & $\begin{array}{l}-0.052(0.013) \\
-3 \cdot 5 * *(3 \cdot 6 * *)\end{array}$ & $\begin{array}{l}-0.056(0.014) \\
-3 \cdot 8 * *(1 \cdot 7)\end{array}$ & $\begin{array}{l}-0 \cdot 02 \\
-3 \cdot 2 * *\end{array}$ & 0.2096 \\
\hline \multicolumn{8}{|c|}{$\begin{array}{l}\text { Table 5. Model parameters for the out-of-town day-trip visitor } \\
\text { group }\end{array}$} & \\
\hline & \multicolumn{4}{|c|}{ Constant coefficient } & \multicolumn{3}{|c|}{ Characteristic variable coefficient } & Adjusted \\
\hline & Taxi & Subway & $\begin{array}{l}\text { Expo shuttle } \\
\text { bus }\end{array}$ & Private car & Walking time & Travel time & Travel cost & \\
\hline Coefficient & 0 & 0.26 & 0.87 & $0 \cdot 11$ & $-0.065(0.014)$ & $-0.044(0.003)$ & -0.032 & $0 \cdot 218$ \\
\hline t-statistic & - & $2 \cdot 7 * *$ & $2 \cdot 1 *$ & $-1.99 *$ & $-3 \cdot 9 * *(2 \cdot 9 * *)$ & $-2 \cdot 4^{*}\left(3 \cdot 2^{* *}\right)$ & $-3 \cdot 8^{* *}$ & \\
\hline
\end{tabular}

* Significant at the $5 \%$ level.

** Significant at the $1 \%$ level.

Table 6. Model parameters for the out-of-town lodging visitor

group

out-of-town lodging visitor groups are shown in Tables 4, 5 and 6 respectively.

The model parameters for the local visitor group show that the coefficient of walking time is much greater than that of travel time, in that walking time has a greater influence on the utility value than travel time. This indicates that local visitors are more sensitive to walking time but less sensitive to waiting and riding time, which may be because a long walking time requires greater endurance, and influences comfort. Local visitors are also sensitive to changes in travel cost.
The model parameters for the out-of-town day-trip visitor group show that walking time and travel time and the influence of the travel cost variable on the utility value had negative values, and that walking time had less influence on the utility value than travel time. This indicates that these visitors are very sensitive to total travel time but less sensitive to the ratio of walking time to total time.

The model parameters for the out-of-town lodging visitor group show that the coefficients of walking time and travel time are both greater than that of travel cost. Clearly, time utility is greater 
than travel cost utility, which indicates that these visitors are strongly sensitive to travel time but relatively less sensitive to travel cost.

\section{Scenario analysis of different traffic policies}

The scenario analysis of different traffic policies was carried out by adopting the Expo visitor trip choice model outlined in the previous section and forecasting visitor classification in accordance with the different visitor departure areas. Three traffic management policies were examined that might promote the switch from individual transport modes, such as a private car or taxi, to public transport modes.

(a) Establishing a restricted traffic zone to increase walking time for those travelling by private car or taxi.

(b) Increasing parking rates around Expo Park and decreasing those at the park and ride Expo shuttle bus transfer points outside the urban area of Shanghai.

(c) Providing Expo shuttle bus priority lanes and giving these buses signal priority to guarantee the travel time of Expo shuttle bus passengers.

\subsection{Initial scenario}

Taking the distance from the Central Railway Station to Expo Park for Shanghai visitors as an example, the travel time for a private car (or taxi) is determined by the actual road travel time, the travel time for the subway is determined using the timetable of the subway operation company, and the travel time for the Expo shuttle bus is assumed to be that of the existing public bus. The taxi cost is calculated in accordance with the current taxi tariff, and the Expo shuttle bus cost takes an assumed value. The private car travel cost consists only of the parking cost, which totals 45 Yuan given a preliminary parking rate of 10 Yuan per hour and $9 \mathrm{~h}$ for visiting Expo Park, and is taken as a one-way travel cost. The assumed time and travel costs for the four trip modes for Shanghai visitors are shown in Table 7.

It is assumed that out-of-town visitors have lodging or transfer at the Hongqiao Pivot to a taxi, the metro system or an Expo shuttle bus, with a time and travel cost calculated as before. The preliminary parking rate at the park and ride point is 40 Yuan per day. The assumed time and travel costs for the four trip modes for out-of-town visitors are shown in Table 8.

The trip mode share for the Expo visitor groups is shown in Table 9.

Table 9 shows that when neither a management measure nor policy is in place, the proportion of private transport is very high. Among the out-of-town day-trip visitors, the sum of the individual trip modes (private car and taxi) is higher than $70 \%$, which would cause great pressure on Shanghai's urban traffic system.

\subsection{Effect of establishing a restricted traffic zone}

The aim of establishing a restricted traffic zone is to increase the walking time of travellers using a taxi or private car without directly influencing either subway or Expo shuttle bus use. It is believed that after setting a $1 \mathrm{~km}$ restricted traffic zone around Expo Park, it would take 20 min to walk from the parking points around Expo Park to the Expo Park entrance, and 15 min to walk from roadside taxi stops to the Expo Park entrance. The trip mode share for the different visitor groups after setting a restricted traffic zone is shown in Table 10.

When a restricted traffic zone is set, the proportions of visitors choosing a taxi or private car decrease. However, the proportion

\begin{tabular}{lccccc}
\hline Trip mode & Waiting time: min & Walking time: min & Riding time: min & Total time: min & Travel cost: Yuan \\
\hline Taxi & 5 & 0 & 30 & 35 & 30 \\
Subway & 5 & 20 & 25 & 50 & 15 \\
Expo shuttle bus & 10 & 5 & 45 & 60 & 12 \\
Private car & 0 & 0 & 40 & 40 & 45
\end{tabular}

Table 7. Initial scenario for local visitors

\begin{tabular}{lcccccc}
\hline Trip mode & $\begin{array}{c}\text { Waiting time: } \\
\text { min }\end{array}$ & $\begin{array}{c}\text { Walking time: } \\
\text { min }\end{array}$ & $\begin{array}{c}\text { Riding time: } \\
\text { min }\end{array}$ & $\begin{array}{c}\text { Total time: } \\
\text { min }\end{array}$ & $\begin{array}{c}\text { Travel cost: } \\
\text { Yuan }\end{array}$ & $\begin{array}{c}\text { P }+R \text { parking rate: } \\
\text { Yuan }\end{array}$ \\
\hline Taxi & 5 & 0 & 30 & 35 & 30 & 20 \\
Subway & 5 & 20 & 25 & 50 & 15 & 20 \\
Expo shuttle bus & 10 & 5 & 45 & 60 & 12 & 20 \\
Private car & 0 & 0 & 40 & 40 & 45 & 0
\end{tabular}

Table 8. Initial scenario for out-of-town visitors 


\section{Departure area}

\begin{tabular}{lccc}
\cline { 2 - 3 } Trip mode & Local visitors & Out-of-town day-trip visitors & Out-of-town lodging visitors \\
\hline Taxi & $6 \cdot 8 \%$ & $34 \cdot 1 \%$ & $25 \cdot 6 \%$ \\
Subway & $25 \cdot 5 \%$ & $12 \cdot 4 \%$ & $18 \cdot 3 \%$ \\
Expo shuttle bus & $36 \cdot 9 \%$ & $16 \cdot 4 \%$ & $30 \cdot 6 \%$ \\
Private car & $30 \cdot 8 \%$ & $37 \cdot 1 \%$ & $25 \cdot 5 \%$
\end{tabular}

Table 9. Trip mode share

\begin{tabular}{|c|c|c|c|c|c|c|}
\hline \multirow{3}{*}{ Trip mode } & \multicolumn{6}{|c|}{ Departure area } \\
\hline & \multicolumn{2}{|c|}{ Local visitors } & \multicolumn{2}{|c|}{ Local visitors } & \multicolumn{2}{|c|}{ Local visitors } \\
\hline & Proportion: \% & Change rate: \% & Proportion: \% & Change rate: \% & Proportion: \% & Change rate: \% \\
\hline Taxi & $4 \cdot 7$ & $-2 \cdot 2$ & $26 \cdot 7$ & $-7 \cdot 4$ & $12 \cdot 8$ & $-12 \cdot 8$ \\
\hline Subway & $36 \cdot 6$ & $11 \cdot 0$ & $27 \cdot 5$ & $15 \cdot 1$ & $26 \cdot 8$ & $8 \cdot 5$ \\
\hline Expo shuttle bus & $39 \cdot 7$ & $2 \cdot 8$ & $27 \cdot 5$ & $11 \cdot 1$ & $49 \cdot 7$ & $19 \cdot 1$ \\
\hline Private car & $19 \cdot 1$ & $-11 \cdot 7$ & $18 \cdot 3$ & -18.8 & $10 \cdot 7$ & $-14 \cdot 8$ \\
\hline
\end{tabular}

of taxi use does not decrease much, whereas the inverse holds for the proportion of private car use. The proportions of visitors choosing the Expo shuttle bus and subway increase somewhat, with the number of visitors switching to the former mode greater than the number of visitors switching to the latter mode.

\subsection{Effect of adjusting parking rates}

Adjusting parking rates mainly influences visitors travelling by private car, encouraging them to switch to more economical trip modes such as the subway or Expo shuttle bus, and has limited influence on those travelling by taxi. It is assumed that the parking rate around Expo Park increases to 20 Yuan per hour, and decreases to 10 Yuan per day at the park and ride points outside the urban area. The trip mode share for the different visitor groups after adjusting the parking rates is shown in Table 11 .

Table 11 shows that adjusting parking rates is effective in reducing private car use but leads to a great increase in taxi use, as those travelling by private car value time more than others, and choose to travel by taxi as a substitute for private car travel to save travel time. This switching choice is especially obvious among out-of-town day-trip visitors, which means that merely increasing or decreasing parking rates will not effectively reduce the total choice share of the private transport modes.

Departure area

Trip mode

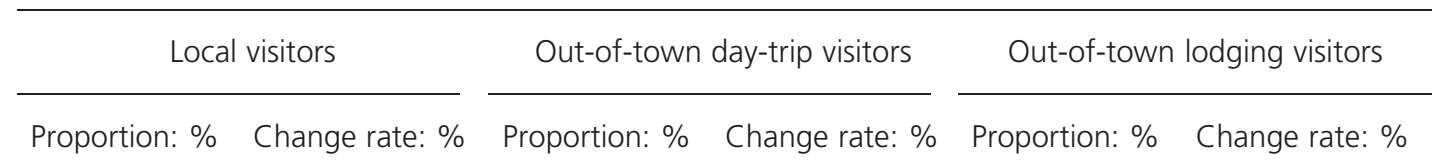

\begin{tabular}{|c|c|c|c|c|c|c|}
\hline Taxi & $9 \cdot 0$ & $2 \cdot 2$ & $43 \cdot 9$ & $9 \cdot 8$ & $31 \cdot 3$ & $5 \cdot 7$ \\
\hline Subway & $35 \cdot 0$ & $9 \cdot 5$ & $17 \cdot 6$ & $5 \cdot 2$ & $23 \cdot 8$ & $5 \cdot 5$ \\
\hline Expo shuttle bus & $43 \cdot 4$ & $6 \cdot 5$ & $22 \cdot 6$ & $6 \cdot 2$ & $39 \cdot 1$ & $8 \cdot 6$ \\
\hline Private car & $12 \cdot 6$ & $-18 \cdot 1$ & $16 \cdot 0$ & $-21 \cdot 2$ & $5 \cdot 8$ & $-19 \cdot 7$ \\
\hline
\end{tabular}

Table 11. Changes in mode share after adjusting parking rates 


\subsection{Effect of giving Expo shuttle buses priority status} Providing priority lanes for and signal priority to Expo shuttle buses can effectively reduce their travel time, and waiting time can be shortened by decreasing the interval between buses. It is assumed that the Expo bus is free for Expo visitors with tickets, and that the riding time of the Expo bus is reduced to $35 \mathrm{~min}$ and the waiting time to $5 \mathrm{~min}$. The trip mode share for the different visitor groups after providing Expo shuttle bus priority are shown in Table 12.

Table 12 shows that giving Expo shuttle buses priority encourages some of those travelling by private car, taxi or subway to switch to travelling by shuttle bus. The proportion of out-of-town lodging visitors switching from the private car, taxi or subway modes is the nearly same. Hence, when developing policies, consideration should be given to offering favourable subway fares while giving the public bus system priority and setting preferential fares to reduce the amount of switching from the subway after giving the Expo shuttle bus service priority.

\subsection{Effect of combining the policies}

The foregoing analyses reveal that relying on only one traffic management measure does not yield a desirable effect. Hence, the three measures are combined to determine their collective effect. The combined time and travel cost conditions are shown in Table 13.

The trip mode share for the different visitor groups after implementing the traffic policies in combination is shown in Table 14.

Departure area

Trip mode

\begin{tabular}{|c|c|c|c|c|}
\hline \multicolumn{2}{|c|}{ Local visitors } & \multicolumn{2}{|c|}{ Out-of-town day-trip visitors } & Out-of-town lodging visitors \\
\hline
\end{tabular}

\begin{tabular}{|c|c|c|c|c|c|c|}
\hline Taxi & $5 \cdot 8$ & $-1 \cdot 0$ & $30 \cdot 7$ & $-3 \cdot 4$ & $16 \cdot 2$ & $-9 \cdot 5$ \\
\hline Subway & $23 \cdot 1$ & $-2 \cdot 5$ & $9 \cdot 6$ & $-2 \cdot 8$ & $10 \cdot 5$ & $-7 \cdot 8$ \\
\hline Expo shuttle bus & $45 \cdot 4$ & $8 \cdot 5$ & $39 \cdot 3$ & $22 \cdot 9$ & $56 \cdot 2$ & $25 \cdot 6$ \\
\hline Private car & $25 \cdot 7$ & $-5 \cdot 0$ & $20 \cdot 5$ & $-16 \cdot 7$ & $17 \cdot 1$ & $-8 \cdot 4$ \\
\hline
\end{tabular}

Table 12. Changes in mode share after providing expo shuttle bus priority

\begin{tabular}{lcccccc}
\hline Trip mode & $\begin{array}{c}\text { Waiting time: } \\
\text { min }\end{array}$ & $\begin{array}{c}\text { Walking time: } \\
\text { min }\end{array}$ & $\begin{array}{c}\text { Riding time: } \\
\text { min }\end{array}$ & Total time: min & $\begin{array}{c}\text { Travel cost: } \\
\text { Yuan }\end{array}$ & $\begin{array}{c}P+R \text { parking rate: } \\
\text { Yuan }\end{array}$ \\
\hline Taxi & 5 & 15 & 30 & 50 & 30 & 10 \\
Subway & 5 & 20 & 25 & 50 & 15 & 10 \\
Expo shuttle bus & 5 & 5 & 35 & 45 & 0 & 10 \\
Private car & 0 & 20 & 40 & 60 & 90 & 0
\end{tabular}

Table 13. Conditions for the combination of traffic policies

\section{Departure area}

Trip mode

Local visitors: \% Out-of-town day-trip visitors: \%

Out-of-town lodging visitors: \%

\begin{tabular}{lrrr}
\hline Taxi & 4.7 & 15.0 & 8.2 \\
Subway & 31.6 & 22.8 & 14.1 \\
Expo shuttle bus & 57.9 & 56.6 & 76.3 \\
Private car & 5.8 & 5.5 & 1.3
\end{tabular}

Table 14. Mode share after implementing the traffic policies in combination 
A comparison of the trip modes before and after the implementation of the traffic policies in combination is shown in Figure 7.

The figure shows that following the implementation of the traffic management policies in combination, taxi and private car use decreases, and the proportion of individual trip modes is reduced to within $10 \%$, which greatly lightens the burden on road traffic. However, among out-of-town visitors, the proportion of those choosing the subway mode increases only slightly. Thus, how the attractiveness of the subway mode can be enhanced and its role

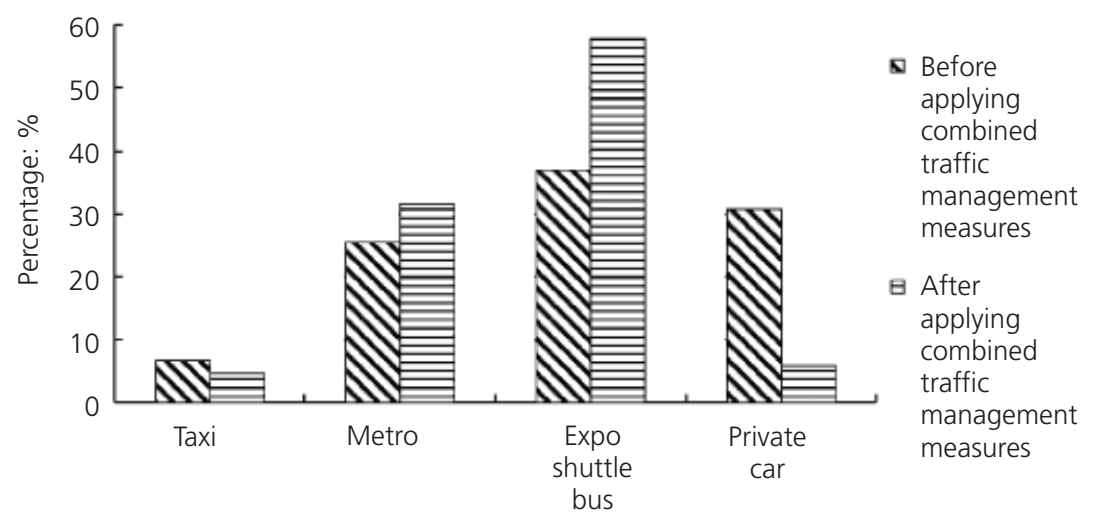

Trip mode (local visitors)

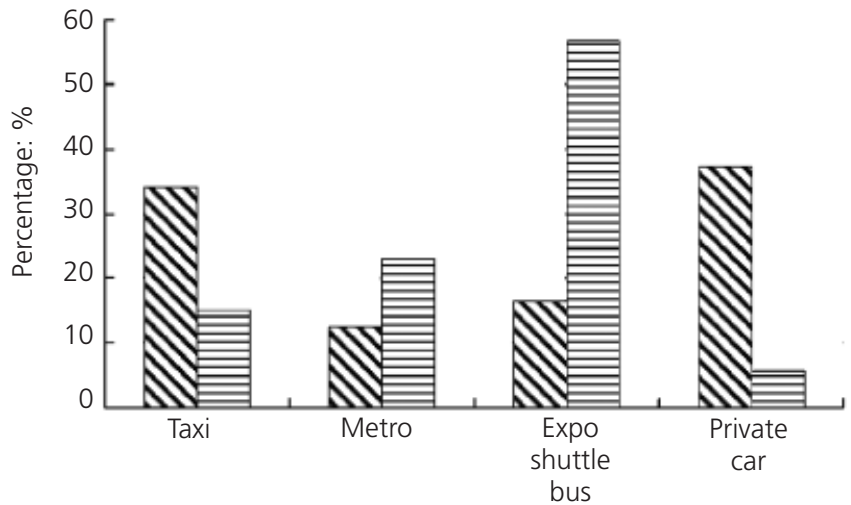

Before applying combined traffic management measures

Trip mode (out-of-town one-day-trip visitors)

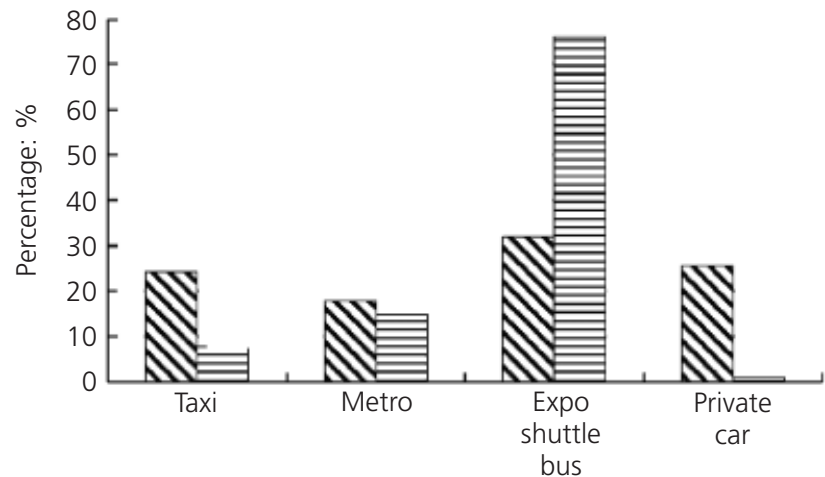

v Before applying combined traffic management measures

= After applying combined traffic management Trip mode (out-of-town lodging visitors) measures 
Transport

Volume 165 Issue TR1
Modelling the mode choice behaviour of

visitors to Expo 2010

Du, Jiang, Sun and Wong in the overall transport system highlighted during Expo 2010 Shanghai remains an issue for further study.

\section{Conclusions}

Based on a detailed analysis of extensive survey data and an indepth exploration of trip mode choice behaviour and its effect on Expo 2010 Shanghai, the following conclusions were drawn.

(a) For an event such as Expo 2010 Shanghai, which involves diverse visitor groups, a single-level stated preference survey is insufficient to separate the variables and obtain a standardised model. Thus, this study develops a two-stage gradual stated preference survey method to determine the main influencing factors and effective variable interval levels based on a first-stage survey that is without constraints and considers differences in departure area trip chain characteristics. This enables the effective development of a second-stage survey with multinomial choices and accurate models for comparison purposes.

(b) The model parameter estimation results for the three visitor groups show that travel time, walking time and travel cost are all influencing factors, but differ in utility among the groups. Local visitors are more sensitive to walking time and total travel cost, out-of-town day-trip visitors are more concerned about total travel time and out-of-town lodging visitors are most sensitive to walking time and total travel time.

(c) The scenario analysis results show that if neither traffic management policies nor control measures are implemented, then the proportion of those using private transport modes is high, at more than $50 \%$ among out-of-town visitors, which would create a great burden on Shanghai's urban traffic network. Establishing a restricted traffic zone, adjusting parking rates and giving Expo shuttle buses priority could encourage some private transport users to switch to public transport, but the effect of these policies differs among the visitor groups and traffic modes. The implementation of these policies in combination effectively controls the proportion of private transport use to within $10 \%$, but has a negative influence on subway use for out-of-town lodging visitors, which is an issue that needs to be addressed.

\section{Acknowledgements}

This paper is based on the results of a research project that was supported by a research grant (60804048) from the National Natural Science Foundation of China (NSFC) and a research grant (NCET-08-0407) from the New Century Excellent Talents in University. The work of the last author was supported by an Outstanding Researcher Award from the University of Hong Kong. The authors take sole responsibility for the views and opinions expressed in the paper. The authors would like to acknowledge the following colleagues from the Traffic Police Office in Shanghai for their support, contributions and ideas: $\mathrm{Mr}$ Li Yin, Mr Xia Haiping, Dr Zhou Xiaopeng and Ms Xiao Bin. We wish to thank the anonymous reviewers for their constructive suggestions.

\section{REFERENCES}

Adler J and Ben-Akiva M (1976) Joint-choice model for frequency, destination, and travel mode for shopping trips. Transportation Research Record 569: 136-150.

Anable J (2005) Complacent car addicts or aspiring environmentalists? Identifying travel behaviour segments using attitude theory. Transport Policy 12(1): 65-78.

Bamberg S and Schmidt P (2001) Theory-driven subgroupspecific evaluation of an intervention to reduce private car use. Journal of Applied Social Psychology 31(6): 1300-1329.

Bhat CR (1997) Work travel mode choice and number of nonwork commute stops. Transportation Research Part B 31(1): 41-54.

Cervero R, Sarmiento OL, Jacoby E, Gomez LF and Neiman A (2009) Influences of built environments on walking and cycling: lessons from Bogota. International Journal of Sustainable Transportation 3(4): 203-226.

Davidson JD (1973) Forecasting traffic on STOL. Operation Research Quarterly 24(4): 561-569.

Fowkes T and Preston J (1991) Novel approaches to forecasting the demand for new local rail services. Transportation Research Part A 25(4): 209-218.

Goodwin PB (1995) Car dependence. Transport Police 2(3): 151152.

Habib KMN and Miller EJ (2009) Modelling activity generation: a utility-based model for activity-agenda formation. Transportmetrica 5(1): 3-23.

Handy S (1996) Methodologies for exploring the link between urban form and travel behavior. Transportation Research Part D 1(2): 151-165.

Hensher DA (1994) Stated preference analysis of travel choice: the state of practice. Transportation 21(2): 107-133.

Hensher DA and Battellino HC (1997) The role of stated preferences and discrete-choice models in identifying individual preferences for traffic-management devices. In Understanding Travel Behaviour in an Era of Change (Stopher P and Lee-Gosselin M (eds)). Elsevier Science, Oxford, pp. 233-256.

Johansson MV, Heldt T and Johansson P (2006) The effects of attitudes and personality traits on mode choice. Transportation Research Part A 40(6): 507-525.

Lu JL and Peeta S (2009) Analysis of the factors that influence the relationship between business air travel and videoconferencing. Transportation Research Part A 43(8): 709-721.

McMillan TE (2007) The relative influence of urban form on a child's travel mode to school. Transportation Research Part A 41(1): 69-79.

McFadden D and Train K (2000) Mixed MNL models for discete response. Journal of Applied Econometrics 15(5): 447-470.

Molin EJE and Timmermans HJP (2009) Hierarchical information integration experiments and integrated choice experiments. Transport Reviews 29(5): 635-655.

Organization Committee of Expo 2010 Shanghai (2005) Registration report of Expo 2010 Shanghai. See http:// 
en.expo2010.cn/expo/expo_english/documents/dc/ userobject1ai48802/00000000.pdf (accessed 27/05/2011).

Ortuzar J de D and Willumsen LG (2001) Modelling Transport, 3rd edn. Wiley, Chichester, UK.

Punj G and Brookes R (2001) Decision constraints and consideration-set formation in consumer durables. Psychology and Marketing 18(8): 843-863.

Raney EA, Mokhtarian PL and Salomon I (2000) Modeling individuals' consideration of strategies to cope with congestion. Transportation Research Part F 3(3): 141-165.

Sakano R and Benjamin JM (2008) A structural equations analysis of revealed and stated travel mode and activity choices. Transportmetrica 4(2): 97-115.

Steg L (2005) Car use: lust and must. Instrumental, symbolic and affective motives for car use. Transportation Research Part $A$ 39(2-3): 147-162.

Swait JD (2001) A non-compensatory choice model incorporating attribute cutoffs. Transportation Research: Part B 35(10):
903-928.

Tam ML, Lam WHK and Lo HP (2008) Modeling air passenger travel behavior on airport ground access mode choices. Transportmetrica 4(2): 135-153.

Van Exel NJA, de Graaf G and Rietveld P (2005) Getting from A to B: operant approaches to travel decision making. Operant Subjectivity 27(4): 194-216.

Wang D, Borgers A, Oppewal H and Timmermans H (2000) A stated choice approach to developing multi-faceted models of activity behaviour. Transportation Research Part A 34(8): 625-643.

Winebrake J, Rothenberg S, Luo J and Green E (2008) Automotive transportation in China: technology, policy, market dynamics, and sustainability. International Journal of Sustainable Transportation 2(4): 213-233.

Yin R, Li KP and Yu J (2007) Traffic forecast for visitors in World Expo 2010 Shanghai arena. Journal of Tongji University (Natural Science) 35(8): 1053-1058.

\section{WHAT DO YOU THINK?}

To discuss this paper, please email up to 500 words to the editor at journals@ice.org.uk. Your contribution will be forwarded to the author(s) for a reply and, if considered appropriate by the editorial panel, will be published as a discussion in a future issue of the journal.

Proceedings journals rely entirely on contributions sent in by civil engineering professionals, academics and students. Papers should be $2000-5000$ words long (briefing papers should be 1000-2000 words long), with adequate illustrations and references. You can submit your paper online via www.icevirtuallibrary.com/content/journals, where you will also find detailed author guidelines. 